\title{
University of New Mexico Cancer Center
}

National Cancer Institute

\section{Source}

National Cancer Institute. University of New Mexico Cancer Center. NCI Thesaurus. Code C105629.

The mission of the University of New Mexico Cancer Center is to reduce the burden of cancer incidence and mortality by discovering the genetic, environmental, social, and behavioral factors that contribute to the distinct cancer patterns and disparities in the American Southwest; translate its scientific discoveries to novel diag nostic, screening, prevention, and therapeutic tools and clinical trials; and assure that all New Mexicans have access to outstanding cancer treatment and clinical trials. It became an $\mathrm{NCl}$ designated cancer center in 2005. It is a University of New Mexico center. 